\title{
Comparison of 2 Clinical Techniques for Treatment of Gingival Recession
}

Hom-Lay Wang, * Pintippa Bunyaratavej, ${ }^{\dagger}{ }^{\dagger}$ Margaret Labadie, ${ }^{*}$ Yu Shyr, ${ }^{\dagger}$ and R. Lamont MacNeil${ }^{\S}$

Background: In early case studies, use of a collagen barrier as a guided tissue regeneration (GTR) material has shown particular promise in procedures aimed at root coverage. The similarities between collagen membrane and subepithelial connective tissue graft (SCTG) have made collagen membrane an attractive and a possible alternative material for root coverage. The purpose of this randomized clinical trial was to compare these 2 techniques, SCTG versus a GTR-based procedure (GTRC), for root coverage/recession treatment.

Methods: Sixteen patients with bilateral Miller's Class I or II (gingival recession $\geq 3.0 \mathrm{~mm}$ ) recession defects were treated either with SCTG or GTRC using a newly designed collagen membrane. Clinical parameters monitored included recession depth (RD), clinical attachment level (CAL), probing depth (PD), width of keratinized gingiva (KG), attached gingiva (AG), and recession width (RW), each measured at the mid-buccal area to the nearest $0.5 \mathrm{~mm}$. Measurements were taken at baseline and 6 months. A standard mucogingival surgical procedure was performed. Data were reported as means $\pm \mathrm{SD}$ and were analyzed using the paired $t$ test for univariate analysis and restricted/residual maximal likelihood (REML)-based mixed effect model for multivariate analysis.

Results: No statistically significant differences were observed in RD, CAL, KG, and AG between test and control groups at either time period. However, SCTG showed significantly more residual PD and more RW gain when compared to GTRC at 6 months. Both treatments resulted in a statistically significant $(P<0.05)$ reduction of recession defects $(2.5 \mathrm{~mm}$ and $2.8 \mathrm{~mm})$, gain of CAL $(2.8 \mathrm{~mm}$ and $2.3 \mathrm{~mm})$, reduction of $\mathrm{RW}(1.9 \mathrm{~mm}$ and $2.7 \mathrm{~mm})$, and increase of KG $(0.7 \mathrm{~mm}$ and $1.1 \mathrm{~mm})$ and AG $(0.7 \mathrm{~mm}$ and $0.5 \mathrm{~mm})$ for GTRC and SCTG, respectively, when comparing 6-month data to baseline. Mean root coverage of $73 \%$ (collagen membrane) and $84 \%$ (subepithelial connective tissue graft) was achieved.

Conclusions: The 2 techniques are clinically comparable. Use of a modified collagen membrane to attain root coverage may alleviate the need for donor site procurement of connective tissue. J Periodontol 2001;72:1301-1311.

\section{KEY WORDS}

Guided tissue regeneration; grafts, connective tissue; collagen/therapeutic use; comparison studies; clinical trials, randomized; follow-up studies.

\footnotetext{
* Department of Periodontics/Prevention/Geriatrics, School of Dentistry, University of Michigan, Ann Arbor, MI

$\dagger$ Department of Periodontology, Faculty of Dentistry, Chiang Mai University, Chiang Mai, Thailand.

‡ Division of Biostatistics, Department of Preventive Medicine, School of Medicine, Vanderbilt

University, Nashville, TN.

$\S$ School of Dental Medicine, University of Connecticut Health Center, Farmington, CT.
}

1 oot coverage is indicated to cover unesthetic, painful, or exposed root surfaces and/or to prevent disease progression in areas where hygiene cannot be adequately maintained. Multiple approaches have often been used to achieve root coverage. Often, multiple grafting procedures are required to achieve optimal results. ${ }^{1,2}$ These techniques include but are not limited to lateral pedicle graft, free gingival graft, and subepithelial connective tissue graft. The subepithelial connective tissue graft (SCTG) technique was introduced to increase the predictability of total root coverage and has been regarded as the standard approach for dealing with this complex problem. ${ }^{3}$ This technique offers a dual blood supply, a better color match, and a high degree of predictable success. Raetzke reported an overall $80 \%$ mean root coverage using this technique, along with an average gain of $3.5 \mathrm{~mm}$ in tissue keratinization. ${ }^{4}$ Nelson later reported $100 \%$ root coverage in areas of $\leq 3$ $\mathrm{mm}$ of recession. ${ }^{5}$ Roots with 4 to $6 \mathrm{~mm}$ of recession had $92 \%$ coverage, and there was $88 \%$ coverage in the more advanced recession $\geq 7$ $\mathrm{mm}$. In a recent study, Harris demonstrated a mean coverage of $94.8 \%$ when this technique was applied. ${ }^{6}$ However, disadvantages associated with the procedure include the need for a second surgical site and morbidity linked with harvesting the autogenous palatal 
donor mucosa. Donor area surgery may result in postsurgical bleeding and patient discomfort. In addition, if the individual has thin palatal tissues overall, it becomes difficult to harvest sufficient donor tissue from one site alone. An additional site may be required, and the patient may have to undergo multiple surgeries in an area to acquire sufficient graft tissue.

Recently, attempts have been made to achieve root coverage using surgical techniques based on the principles of guided tissue regeneration (GTR). ${ }^{7-15}$ These procedures have employed a variety of occlusive barrier products including non-resorbable (e.g., expanded polytetrafluoroethylene [ePTFE $\left.{ }^{\|}\right]$) and bioabsorbable (e.g., collagen, polylactide or polyglycolide polymer) materials. ${ }^{9-12}$ Controlled clinical trials have indicated that GTR-based root coverage procedures respond well especially in deep and narrower recession defects. ${ }^{13}$ Similar results were reported when GTR-based techniques were compared to traditional root coverage procedures. $^{6,14,16,17}$ GTR therapy offers an additional benefit through its potential of promoting new attachment formation along the previously denuded root surface, which rarely occurs when a SCTG is utilized. ${ }^{18}$ For example, the type of healing observed following transposition of a pedicle graft is usually formation of a long junctional epithelium with a minimal amount of new connective tissue attachment. ${ }^{2}$ In comparison, GTR-treated sites typically show healing characterized by varying amounts of new bone, new cementum, and new periodontal ligament. ${ }^{10,18}$ It appears then that GTR therapy is a legitimate approach toward managing the problem of root coverage and that clinical outcomes may be even more favorable than those achieved with traditional methods.

Non-resorbable ePTFE represents the first generation of materials used for GTR-based root coverage procedures. ePTFE has shown encouraging results but is limited by a number of clinical and biological deficiencies. The need for a secondary surgical procedure to retrieve the material has limited its usage and may further jeopardize wound healing and clinical outcomes. These deficiencies have led to a search for alternative, second-generation materials that are occlusive but also biodegradable and "tissue friendly." A number of naturally bioabsorbable materials, including synthetic polymers and animal-derived collagen products, have been introduced as GTR barriers over the past decade. In clinical testing, these materials have shown results comparable to traditional non-resorbable barrier materials in the treatment of infrabony defects and furcation lesions. ${ }^{19-21}$

Collagen is the predominant protein in human connective tissue including periodontal tissues and, as such, is well tolerated by gingival tissue and incorporated as a native structure. It is physiologically bioabsorbable and has been successfully used as a GTR barrier and, in preliminary studies, as an aid in root coverage techniques. ${ }^{12,22}$ If it were employed as a barrier method in GTR root coverage, a collagen barrier would eliminate the need for a second surgical site to harvest autogenous connective tissue donor material. It is also anticipated that when placed as a subepithelial graft, keloid formation will be reduced and the common need for a secondary surgical procedure, either to reposition the graft coronally to obtain adequate root coverage or to reduce thickness, would be reduced. Collagen also encourages autogenous connective tissue and epithelial cells to attach and migrate over its surface. ${ }^{23}$ These chemotactic properties may reduce the incidence of membrane exposure and bacterial contamination, 2 sequelae that are known to inhibit tissue regeneration. Through its ability to aggregate platelets, collagen has been shown to act as a hemostatic agent that promotes initial clot formation and wound stability. ${ }^{24}$ It is also possible that collagen barriers may act similarly to subepithelial connective tissue grafts by providing a collagenous scaffold for tissue repair and may secondarily augment the volume (thickness) of gingival tissue following in vivo expansion, enzyme degradation, and eventual replacement by the surrounding connective tissue. ${ }^{25}$ These properties collectively make collagen attractive for use in GTR-based root coverage procedures.

Shieh et al. and Wang et al. showed that collagen can be effectively used as a graft material for root coverage after 6 months, ${ }^{12,22}$ while Zahedi et al. reported mean root coverage of $82.2 \%$ after 2 years. ${ }^{26}$ Since neither of these studies included a control group, it is yet unknown if the GTR-based procedure is comparable to conventional procedures. Özcan et al. compared the use of collagen membranes containing fibrin/fibronectin plus tetracycline root conditioning to coronally positioned flaps. ${ }^{27}$ They found no significant differences between groups with regard to mean root coverage. Nonetheless, significantly more gain in clinical attachment was found in the collagen membrane group compared to the coronally positioned flap group $(4.21 \mathrm{~mm}$ versus $2.86 \mathrm{~mm}$ ). Recently, Tatakis and Trombelli compared the SCTG and GTR techniques using polyglycolic acid barrier. They reported that both approaches resulted in a similar percentage of root coverage, while the prevalence of complete root coverage consistently favored SCTG treatment. ${ }^{28}$ Nonetheless, at this point, only limited information is available on differences between collagen membrane and traditional soft tissue grafting procedures, especially SCTG.

Therefore, the purpose of this study was to clinically evaluate the utility of a GTR technique using a newly designed, double thickness, type I collagen membrane in the treatment of gingival recession. In

|| Gore-Tex Periodontal Material, W. L. Gore $\varepsilon$ Associates Inc., Flagstaff, AZ. 
this study, the percentage of root coverage with respect to coronal gain of keratinized tissue height and esthetic blending is compared between a GTR technique using a collagen membrane and a subepithelial graft technique using autogenous connective tissue.

\section{MATERIALS AND METHODS}

\section{Subjects}

The research protocol herein described was approved by the university committee governing the use of human subjects in clinical experimentation. Sixteen systemically healthy patients with bilateral recession defects ( 6 males and 10 females, 30 to 54 years of age, mean age 40.6 years) were selected from the patient pool of the Graduate Periodontic Clinic at the University of Michigan School of Dentistry. Patient selection criteria for this clinical study included: 1) two buccal recession defects ( $\geq 3 \mathrm{~mm}$ ) classified as either Miller's Class I or II; ${ }^{29} 2$ ) radiographic evidence of sufficient interdental bone (the distance between crestal bone and cemento-enamel junction $\leq 2 \mathrm{~mm}$ ); 3) clinical indication and/or patient request for recession coverage; and 4) sufficient palatal donor tissue available for the indicated connective tissue graft. Patients with any of the following conditions were excluded from the study: 1) potential medical complications; 2) known allergy to bovine products; 3 ) history of anaphylactoid reaction; 4) pregnancy; 5) use of any tobacco products within the last 30 days; 6 ) evidence of clinically significant (as defined by the investigators) renal, hepatic, cardiac, endocrine, hematologic, autoimmune, or any systemic disease that would make interpretation of the protocol or results difficult; 7) inability to provide informed consent; or 8) participation in another clinical trial using an investigational new drug or device within 30 days of entrance into the study. Each participant completed initial therapy consisting of oral hygiene instruction, scaling and root planing, polishing, and occlusal adjustment as needed prior to consideration for entry into the study. Following this therapy and achievement of a modified O'Leary plaque score $^{30}$ of $85 \%$ or better, patients signed a written consent form to have one recession defect treated with the GTR-collagen membrane technique (GTRC) and the other with connective tissue harvested from another surgical site in their mouth (the palate). Both recession sites were treated at the same visit.

\section{Clinical Measurements}

Data were collected at each visit on standard data recording sheets. The data collector was blinded to the treatment type and took all measurements during the study. All clinical measures were made to the nearest $0.5 \mathrm{~mm}$ with a standard UNC manual probe. Prior to the study, the examiner was calibrated to reduce intraexaminer error (kappa $>0.75$ ) to establish reliability and consistency. Each subject was examined throughout the study by the same examiner (ML).

Gingival depths were measured in the following manner. At baseline, 1, 2, 4 weeks and 3 and 6 months postsurgery, tissue was evaluated utilizing the following indices: plaque index (PI) according to Silness and Löe, ${ }^{31}$ modified gingival index (MGI) as described by Lobene et al., ${ }^{32}$ and sulcus bleeding index using the criteria by Mühlemann and Son. ${ }^{33}$ In addition, at baseline and 3 and 6 months postsurgically as part of the patient's recall examination and maintenance visits, the following clinical measurements were recorded: recession depth (RD), recession width (RW), width of keratinized gingiva (KG), clinical attachment level (CAL), and probing sulcus depth (PD). Measurement of RD and CAL was recorded relative to the cementoenamel junction (CEJ). RD was measured from the mid-facial point of the CEJ to the free gingival margin (FGM). The width (RW) was recorded at a level of $1 \mathrm{~mm}$ apical to the CEJ. The width of keratinized tissue $(K G)$ was determined by subtracting the RD measure from the CEJ-MGJ (mucogingival junction). The difference between CEJ-MGJ and CEJ-PD denoted the width of attached gingiva (AG).

Additional clinical data were obtained via photographs taken at each postoperative visit. Subjective evaluation of color match, contour, consistency, contiguity or blending, and degree of keloid formation was scored at the 6-month postsurgical interval. An independent periodontist was asked to rate the color match as excellent, good, adequate, or unsatisfactory. Contour was judged based upon the presence or absence of a scalloped, knife-edged, graft gingival margin. Consistency was described as firm or spongy. Contiguity was evaluated based upon the confluence between the graft and recipient flap and rated with yes or no. Keloid was scored as absent or present. Patient satisfaction with the esthetics (color match, overall satisfaction, and amount of root coverage) was recorded. Kodachrome slides were taken at each visit as perpendicular to the tooth as possible.

At 6 months post-treatment, the percentage of root coverage was calculated according to the following formula:

$\frac{\begin{array}{c}\text { (postoperative recession depth }- \\ \text { preoperative recession depth) }\end{array}}{\text { preoperative recession depth }} \times 100 \%$

\section{Surgical Protocol (Figures 1, 2, and 3)}

All surgical procedures were performed by one surgeon (HLW). Both recession sites were prepared similar to the technique described by Langer and Langer. ${ }^{3}$ Briefly, after adequate local anesthesia was obtained, sulcular incisions were made on the recipient teeth and joined to horizontal incisions extending into the 

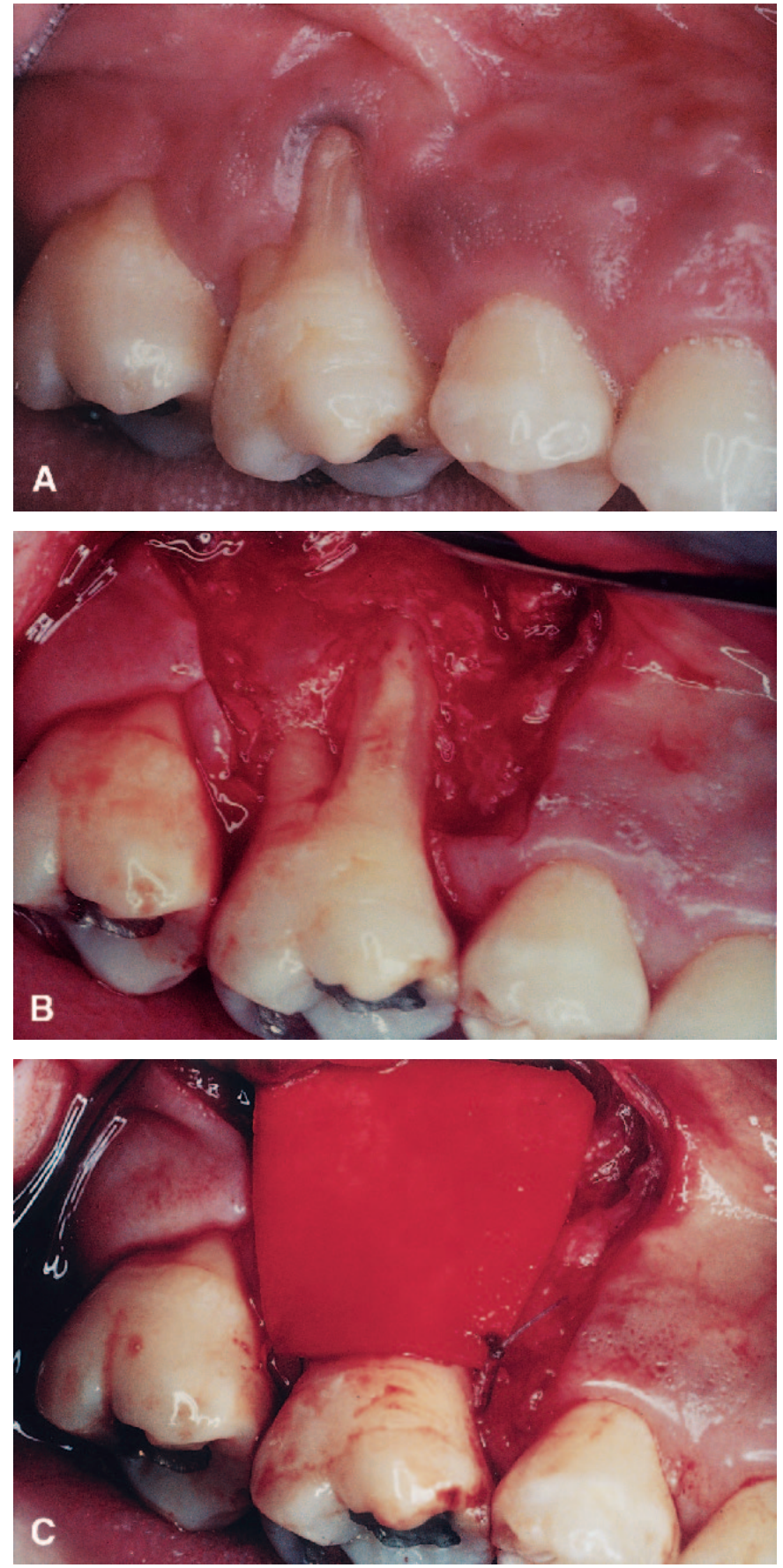

adjacent interdental areas slightly coronal to the tooth's CEJ. The horizontal incisions were connected to 2 vertical incisions that began at the line angles of the adjacent teeth. A $2 \mathrm{~mm}$ collar of bone and periodontal ligament was exposed (full-thickness flap) on all sides of the dehiscence/recession. A trapezoidal-shaped, partial-thickness flap was elevated to a level $3 \mathrm{~mm}$ more apical to the expected bone in the recession/ dehiscence area, providing a vascular connective tissue bed for placement of the selected graft material. The exposed, affected root surface was scaled and planed with ultrasonics, rotary burs, and/or curets to produce
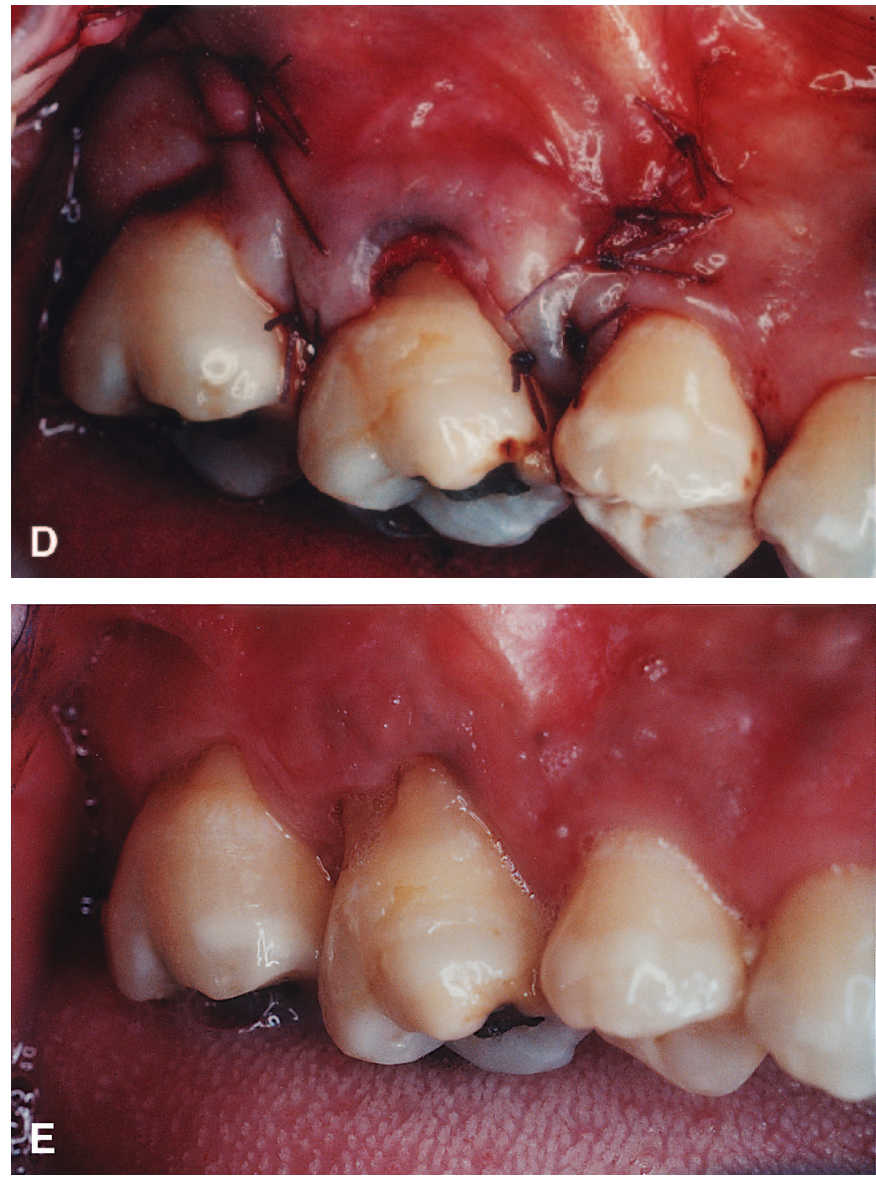

\section{Figure I.}

GTR-based root coverage procedure utilizing newly designed, doublethickness collagen membrane (GTRC). $\boldsymbol{A}$. Presurgery shows $7 \mathrm{~mm}$ of gingival recession (patient's right side, tooth \#3); B. full-thickness flap is raised and root surface debrided; $\boldsymbol{C}$. collagen membrane is placed and sutured with 5-0 suture; $\boldsymbol{D}$. flap coronally advanced and sutured; E. healing at 6 months showed $5 \mathrm{~mm}$ of root coverage.

a decontaminated, smooth, and flattened surface. No chemical root treatment was performed.

After all recipient site preparation was completed, the selection of collagen membrane or autogenous palatal donor graft was randomly assigned by a coin toss. The defect on the patient's right side was first assigned through this approach, while the defect on the opposite side received the other treatment choice. The collagen membrane used here is a newly designed, double-thickness collagen membranell (prepared from

If Sulzer Dental Inc., Carlsbad, CA. 

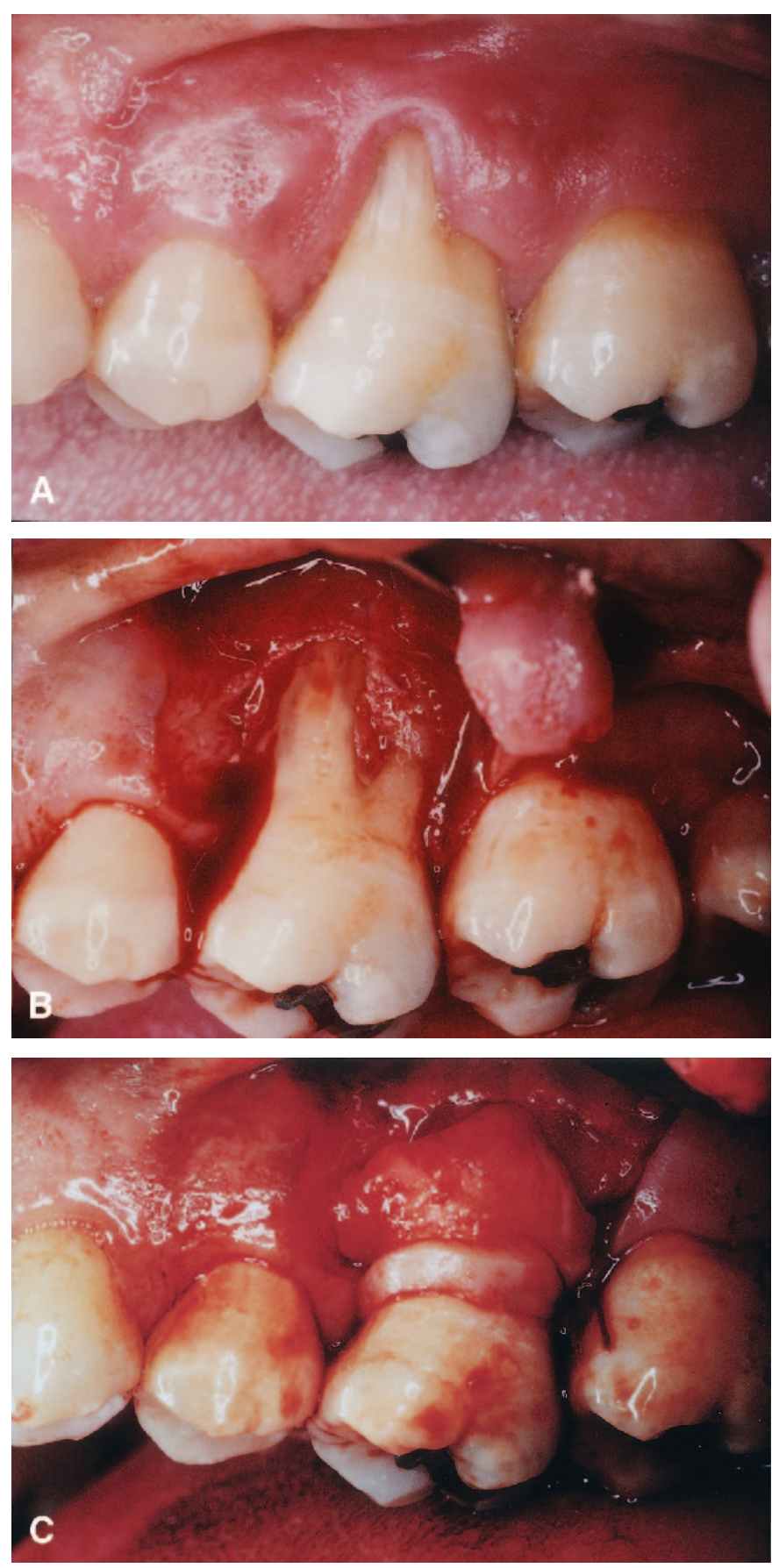

purified bovine Achilles tendon in a chemically crosslinked form and supplied in individual $20 \mathrm{~mm} \times 15$ $\mathrm{mm} \times 0.40$ to $0.50 \mathrm{~mm}$ sterile pieces; it differs from original collagen membrane ${ }^{\#}$ by its double thickness). The donor SCTG graft was harvested as described by Langer and Langer. ${ }^{3}$ Donor tissue thickness close to $1.5 \mathrm{~mm}$ was achieved by selective trimming of the harvested tissue.

Both grafts were shaped to fit their respective recipient sites so that the exposed root area up to the CEJ or expected level of root coverage was covered. The grafts extended apically and laterally beyond the bony
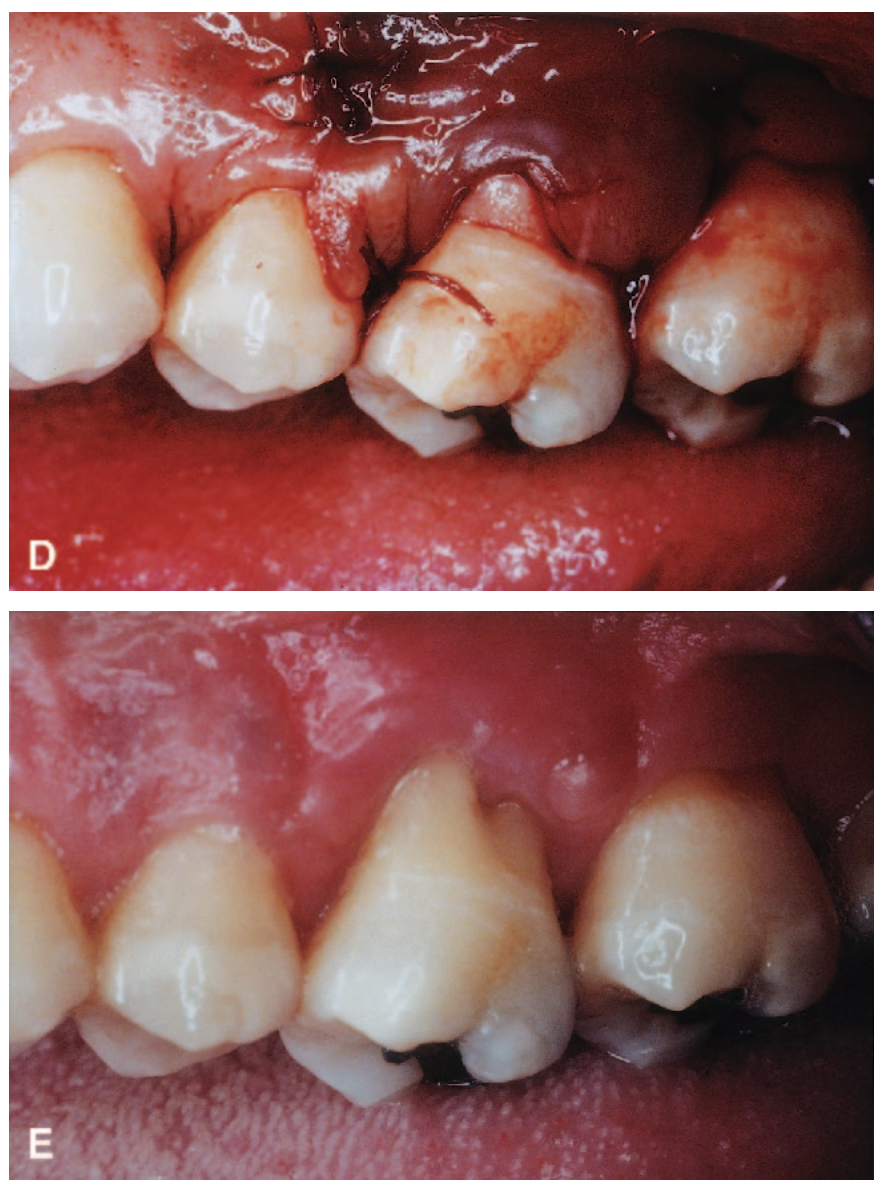

Figure 2.

Subepithelial connective tissue graft procedure (SCTG). A. Presurgery shows $7 \mathrm{~mm}$ of gingival recession (patient's left side, tooth \# I 4); $\boldsymbol{B}$. full-thickness flap is raised and root surface debrided; $\boldsymbol{C}$. connective tissue graft harvested and sutured with 5-0 suture; $\boldsymbol{D}$. flap coronally advanced and sutured; $\boldsymbol{E}$. healing at 6 months showed $5 \mathrm{~mm}$ of root coverage

margins of the dehiscence/recession defect by at least $1 \mathrm{~mm}$ so that two-thirds of the graft was covered by the host flaps. The collagen membranes and the autogenous connective tissue grafts were fixed in place with coronal tacking sutures through the interdental papillae using a resorbable 5-0 suture. ** The flap was then coronally positioned to cover the membrane/SCTG and secured with two 5-0 sutures** at the mesial and distal angles, respectively. Care was taken to ensure that

\# BioMend, Sulzer Dental Inc.

** Vicryl, Johnson \& Johnson, Somerville, NJ. 

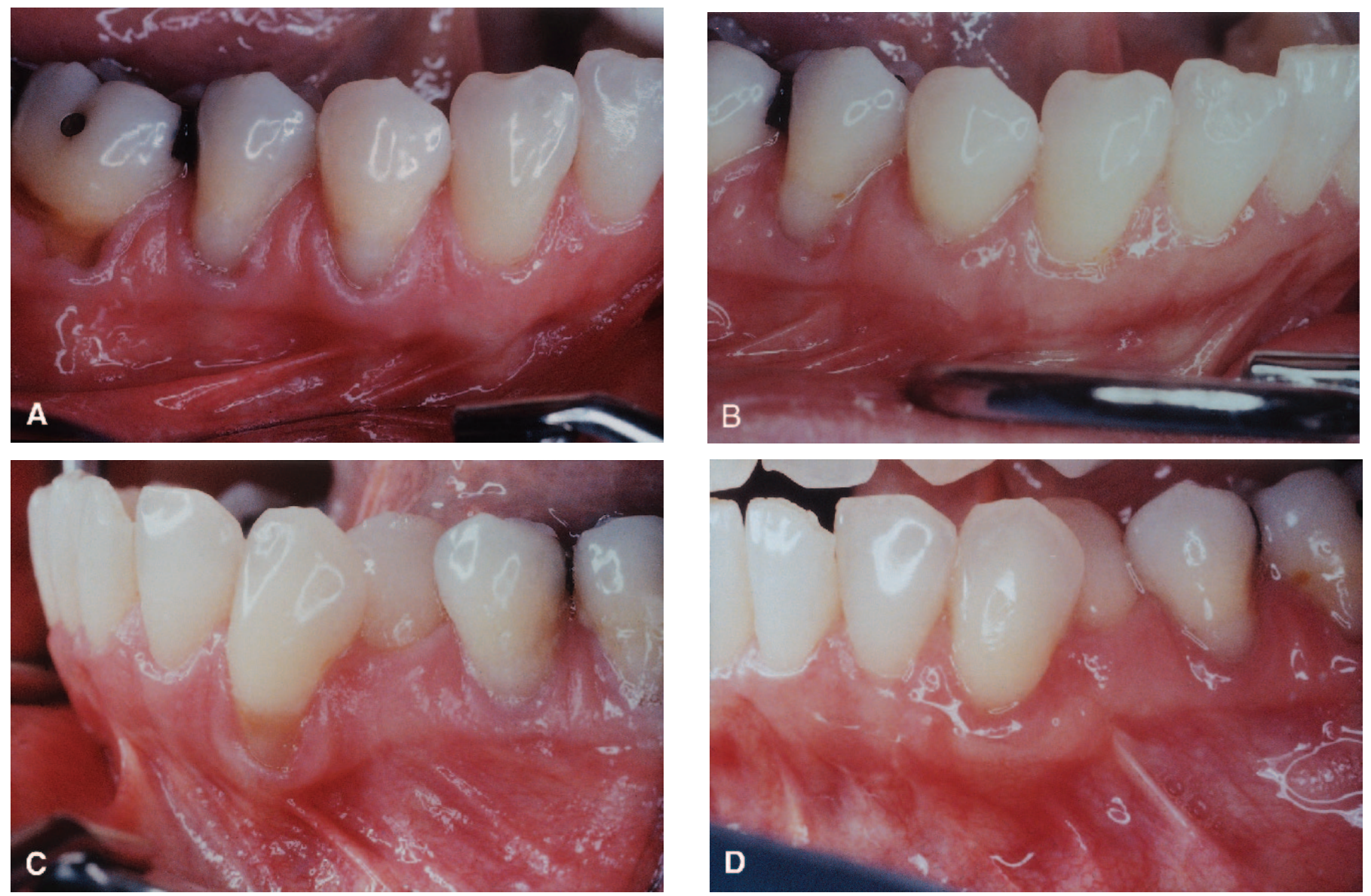

\section{Figure 3.}

Results at 6 months for both GTRC and SCTG in the same individual. A. Presurgery (patient's right side, tooth \#28); composite restoration was removed and collagen membrane was placed and sutured; B. healing at 6 months showed $100 \%$ root coverage; $\boldsymbol{C}$. presurgery (patient's left side, tooth \#22); site was treated by subepithelial connective tissue graft; $\mathbf{D}$. healing at 6 months showed $100 \%$ root coverage.

the flap was free of tension. Following closure of the recipient sites, the palatal donor site was treated in the appropriate manner. Sterile dry foil was adapted and periodontal dressing placed over the recipient sites to protect the wounds from any potential trauma.

After surgery, routine written and oral postoperative care instructions were given to the patients. A nonsteroid anti-inflammatory analgesic was prescribed. Amoxicillin or necessary substitute antibiotics were prescribed only in those cases where a concern for infection developed. Patients were instructed in postoperative home care including a recommendation to refrain from mechanical cleaning on the surgical areas. Warm saltwater rinses and topical, warm saltwater application with a cotton tip were used instead of mouthrinse for the first month. After 28 days, patients were instructed to resume routine oral hygiene with encouragement to rinse twice daily with $0.12 \%$ chlorhexidine gluconate mouthrinse. ${ }^{\dagger \dagger}$ Patients were seen at $1,2,4$ weeks and 3 and 6 months for postoperative care and clinical measurements. Dressing materials and sutures were removed at 7 to 10 days after surgery. Professional prophylaxis without prophy paste and reinforcement of oral hygiene instructions were also performed if indicated (i.e., visible supragingival plaque or calculus present) at each post-treatment visit.

\section{Statistical Analysis}

Prior to the initiation of the study, a statistical power analysis was utilized to determine the sample size. This is performed at $\alpha$ (the probability of type I error) = 0.05 , and at $\beta$ (the probability of type II error) $=0.20$, which is equal to $80 \%$ of power. With the estimated standard deviation of the population set as $0.7 \mathrm{~mm}$ (from a previous study), ${ }^{12}$ the minimum difference for detecting a statistical significance was set at $1 \mathrm{~mm}$ between treatments. This analysis indicated that 16 subjects were needed in this study to show a statistical difference. Data were reported as means $\pm S D$, and a statistical software program ${ }^{\ddagger}$ was used for all analy-

$\dagger \dagger$ Peridex, Procter $\mathcal{E}$ Gamble, Cincinnati, OH.

玤 SAS 6.12, SAS Institute, Inc., Cary, NC. 
sis. Data were analyzed using the paired $t$ test for univariate analysis and restricted/ residual maximal likelihood (REML)-based mixed effect model for multivariate analysis. Significance was reported at the $95 \%$ confidence level.

\section{RESULTS}

Sixteen patients (mean age $40.6 \pm 9.15$ ) with bilateral, similar buccal gingival recession defects $\geq 3.0 \mathrm{~mm}$ (Miller's Class I or II) were studied. During the course of this study, one subject experienced an unexpected adverse postsurgical swelling in the SCTG site. In addition, one patient had a postsurgical ecchymosis in the SCTG-treated site. Both complications were treated with antibiotics and healing on both sites was uneventful. However, the result of root coverage was less favorable than that observed at "uneventful" sites.

Tables 1 and 2 show the clinical parameters at baseline and 6 months. At baseline, no statistically significant differences between study groups were found for any of the parameters except PD and CAL. Recession depths (Table 1) at GTRC-treated sites decreased from $3.7 \pm 1.1 \mathrm{~mm}$ to $1.1 \pm 1.2$ $\mathrm{mm}$, a reduction of $2.5 \pm 0.7 \mathrm{~mm}$, corresponding to a mean root coverage of $73 \pm 26 \%$ (Table 3 ). In sites treated with SCTG, mean recession decreased from $3.4 \pm 1.0 \mathrm{~mm}$ to $0.7 \pm 1.2 \mathrm{~mm}$, a reduction of $2.8 \pm 0.8 \mathrm{~mm}$, corresponding to a mean root coverage of $84 \pm 25 \%$ (Table 3 ). The difference between GTRC and SCTG still favored SCTG, but the difference was not statistically significant. Table 3 revealed 6 -month results for both treatments. Both treatment groups showed a statistically significant reduction $(P<0.05)$ of $\mathrm{RD}$. Table 3 lists the percentage of root coverage in each individually treated site. As indicated in Table 4, 7 out of $16(43.8 \%)$ in both groups achieved $100 \%$ coverage, while 14 out of $16(87.5 \%)$ gained $\geq 50 \%$ root coverage in both treated groups. However, only 7 GTRC sites $(43.8 \%)$ gained $>75 \%$ root coverage as compared to $11(68.8 \%)$ SCTG-grafted sites.

For recession width, both groups showed statistical improvement $(P<0.05)$ at 6 months when compared to baseline. SCTG demonstrated a statistically significant reduction of RW when compared to GTRC at 6 months. A significant increase of keratinized gingival
Table I.

Gingival Recession at Baseline and 6 Months Postoperatively (data are reported as means \pm SD in $\mathrm{mm}$ )

\begin{tabular}{|c|c|c|c|}
\hline Treatment & GTRC & SCTG & $\begin{array}{c}\text { Difference } \\
\text { (GTRC-SCTG) }\end{array}$ \\
\hline \multicolumn{4}{|l|}{ Recession depth } \\
\hline Baseline & $3.7 \pm 1.1$ & $3.4 \pm 1.0$ & $0.2 \pm 0.6$ \\
\hline 6 months & $1.1 \pm 1.2$ & $0.7 \pm 1.2$ & $0.4 \pm 1.2$ \\
\hline Difference (baseline-6 month) & $2.5 \pm 0.7 *+$ & $2.8 \pm 0.8 * \dagger$ & $-0.2 \pm 1.1$ \\
\hline \multicolumn{4}{|l|}{ Recession width } \\
\hline Baseline & $3.4 \pm 0.9$ & $3.5 \pm 0.8$ & $0.0 \pm 0.7$ \\
\hline 6 months & $1.5 \pm 1.9$ & $0.8 \pm 1.4$ & $0.7 \pm 1.3 *$ \\
\hline Difference (baseline-6 month) & $1.9 \pm 1.7 *$ & $2.7 \pm 1.2^{*}$ & $-0.8 \pm 1.3 * \dagger$ \\
\hline \multicolumn{4}{|l|}{ Keratinized gingiva } \\
\hline Baseline & $2.8 \pm 1.4$ & $2.5 \pm 1.2$ & $0.3 \pm 0.5$ \\
\hline 6 months & $3.5 \pm 1.0$ & $3.7 \pm 1.6$ & $-0.1 \pm 1.0$ \\
\hline Difference (baseline-6 month) & $-0.7 \pm 1.7$ & $-1.1 \pm 2.0 * \dagger$ & $0.4 \pm 1.0$ \\
\hline \multicolumn{4}{|l|}{ Attached gingiva } \\
\hline Baseline & $1.3 \pm 1.0$ & $1.3 \pm 0.8$ & $0.0 \pm 0.8$ \\
\hline 6 months & $2.0 \pm 1.3$ & $1.8 \pm 1.7$ & $0.2 \pm 1.2$ \\
\hline Difference (baseline-6 month) & $-0.7 \pm 1.5$ & $-0.5 \pm 2.1$ & $-0.2 \pm 1.3$ \\
\hline
\end{tabular}

* Statistical difference at $P<0.05$ level.

$\dagger$ Due to rounding of data.

\section{Clinical Parameters of Treated Sites at Baseline and 6 Months Postoperatively (data are reported as means \pm $\mathrm{SD}$ in $\mathrm{mm}$ )}

\begin{tabular}{lccc}
\hline Treatment & GTRC & SCTG & Difference (GTRC-SCTG) \\
\hline Clinical attachment level & & & \\
$\quad$ Baseline & $5.4 \pm 1.2$ & $4.8 \pm 1.2$ & $0.6 \pm 0.6^{*}$ \\
$\quad 6$ months & $2.6 \pm 1.2$ & $2.5 \pm 1.4$ & $0.1 \pm 1.2$ \\
$\quad$ Difference (baseline-6 month) & $2.8 \pm 0.7^{*}$ & $2.3 \pm 1.0^{*}$ & $0.4 \pm 1.1^{\dagger}$ \\
& & & \\
Probing depth & $1.8 \pm 0.4$ & $1.4 \pm 0.5$ & $0.3 \pm 0.5^{*}$ \\
$\quad$ Baseline & $1.5 \pm 0.5$ & $1.8 \pm 1.4$ & $-0.3 \pm 0.6^{*}$ \\
$\quad 6$ months & $0.3 \pm 0.3$ & $-0.4 \pm 0.6^{*}$ & $0.7 \pm 0.6^{* \dagger}$ \\
$\quad$ Difference (baseline-6 months) & & & \\
\hline
\end{tabular}

* Statistical difference at $P<0.05$ level.

$\dagger$ Due to rounding of data. 
Table 3.

\section{Individually Treated Sites; Percentage of Root Coverage After 6 Months Compared to Baseline}

\begin{tabular}{lcc}
\hline Patient & GTRC & SCTG \\
\hline 001 & 50 & 100 \\
002 & 50 & 33 \\
003 & 67 & 83 \\
004 & 100 & 60 \\
005 & 100 & 83 \\
006 & 100 & 100 \\
007 & 100 & 100 \\
008 & 50 & 87 \\
009 & 50 & 67 \\
010 & 71 & 100 \\
011 & 43 & 38 \\
012 & 100 & 100 \\
013 & 100 & 83 \\
014 & 33 & 100 \\
015 & 50 & 73 \\
016 & 100 & 100 \\
Average (mean \pm SD) & $73 \pm 26$ & 84 \\
\hline
\end{tabular}

line. GTRC and SCTG-treated sites gained $2.8 \mathrm{~mm}$ (from $5.4 \mathrm{~mm}$ to $2.6 \mathrm{~mm}$ ) or $2.3 \mathrm{~mm}$ (from $4.8 \mathrm{~mm}$ to $2.5 \mathrm{~mm}$ ) of CAL, respectively. No differences were found between the groups. GTRC-treated sites showed a reduction of $0.3 \pm 0.3 \mathrm{~mm}$ PD (Table 2), while SCTGtreated sites showed an increase of $0.4 \pm 0.6 \mathrm{~mm}$. The difference between both treatments was statistically significant $(P<0.05)$.

No statistical difference was noted in GI, PI, and BI (Table 5) between groups when compared to 3 different time points $(0,3$, and 6 months).

\section{Periodontist Preference}

Table 6 lists the subjective evaluation of color match, contour, consistency, contiguity or blending, and degree of keloid formation. When an independent periodontist rated the treatment results at 6 months, 15 out of 16 GTRC sites had excellent color match and only 11 SCTG sites reported the same. Good contour was noted in 15 GTRC sites versus 13 SCTG sites. Tissues showed firm consistency in all sites treated by either technique. Sixteen GTRC-treated sites were rated as having an
Table 4.

\section{Percentage of Root Coverage After 6 Months}

\begin{tabular}{cccccc}
\hline Group & $N$ & $100 \%$ & $>75 \%$ & $\geq 50 \%$ & $<50 \%$ \\
\hline GTRC & 16 & $7(43.8)$ & $7(43.8)$ & $14(87.5)$ & $2(12.5)$ \\
SCTG & 16 & $7(43.8)$ & $11(68.8)$ & $14(87.5)$ & $2(12.5)$ \\
\hline
\end{tabular}

acceptable blend as compared to 14 SCTG sites. Keloid formation was noted in only one SCTG site.

\section{Patient Satisfaction}

Patient satisfaction with esthetics (color match, overall satisfaction, and amount of root coverage) was the same for both treatments (Table 7). However, patients expressed greater satisfaction overall with GTRC.

\section{DISCUSSION}

The purpose of this randomized controlled clinical trial was to compare the clinical outcomes of traditional subepithelial connective tissue graft (SCTG) versus a GTR technique using a newly designed, double-thickness collagen membrane (GTRC) for the treatment of buccal gingival recessions. Results obtained from this study indicated that both GTRC and SCTG can be successfully used to treat periodontal recession defects. This finding is similar to that reported by Tatakis and Trombelli, who indicated that both SCTG and GTR can be used to achieve root coverage. ${ }^{28}$ As outlined earlier, a GTR technique could offer several advantages over SCTG, including elimination of the need for a second surgical site(s) for harvesting graft and associated morbidity, less postsurgical trauma and discomfort, reduction in operatory time, and an increase in acceptance of the procedure by patients. Our results suggest that this technique may eliminate the need for use of autologous tissue in root coverage procedures.

Data from this study demonstrated that a significant improvement was found in RD $(2.5 \mathrm{~mm}$ for GTRC and $2.8 \mathrm{~mm}$ for SCTG) and in the percentage of root coverage ( $73 \%$ for GTRC and $84 \%$ for SCTG). Although no statistically significant differences were found between the groups, results tended to favor the SCTG procedure. Overall, $43.8 \%$ of sites in both treatment groups achieved $100 \%$ root coverage, and $87.5 \%$ of sites gained $\geq 50 \%$ root coverage. Nearly $70 \%(68.8 \%)$ of SCTGtreated sites achieved $>75 \%$ root coverage as compared to $43.8 \%$ of GTRC sites. This difference might be explained by the influence of tissue thickness. As described by Harris, when GTR-based root coverage was used to treat buccal recession defects, areas with thin $(<0.5 \mathrm{~mm})$ tissue thickness gained only $26.7 \%$ root coverage as compared to $95.9 \%$ root coverage in thick $\left(\geq 0.5 \mathrm{~mm}\right.$ ) tissue. ${ }^{6}$ Although current flap thickness was 
Table 5.

\section{Clinical Indices of Treated Sites at Different Time Points (data are reported as means $\pm \mathrm{SD}$ )}

\begin{tabular}{lcccccc}
\hline & \multicolumn{2}{c}{ GI } & \multicolumn{2}{c}{ PI } & \multicolumn{2}{c}{ BI } \\
\cline { 2 - 7 } & GTRC & SCTG & GTRC & SCTG & GTRC & SCTG \\
\hline Baseline & $0.8 \pm 0.4$ & $0.8 \pm 0.4$ & $0.2 \pm 0.4$ & $0.1 \pm 0.3$ & $0.1 \pm 0.3$ & $0.2 \pm 0.4$ \\
I week post-op & $1.8 \pm 0.8$ & $1.9 \pm 0.8$ & $0.6 \pm 0.6$ & $0.6 \pm 0.7$ & N/A & N/A \\
2 weeks post-op & $1.3 \pm 0.7$ & $1.6 \pm 0.6$ & $0.4 \pm 0.5$ & $0.3 \pm 0.6$ & N/A & N/A \\
4 weeks post-op & $0.8 \pm 0.5$ & $1.1 \pm 0.4$ & $0.4 \pm 0.6$ & $0.4 \pm 0.5$ & N/A & N/A \\
3 months post-op & $0.6 \pm 0.7$ & $0.6 \pm 0.7$ & $0.4 \pm 0.5$ & $0.4 \pm 0.6$ & $0.1 \pm 0.3$ & $0.1 \pm 0.3$ \\
6 months post-op & $0.7 \pm 0.6$ & $0.6 \pm 0.6$ & $0.4 \pm 0.6$ & $0.3 \pm 0.5$ & $0.2 \pm 0.4$ & $0.1 \pm 0.3$ \\
\hline
\end{tabular}

No statistical difference was noted in GI, PI, and BI between groups when compared to 3 different time points ( 0,3 , and 6 months).

Table 6.

Subjective Evaluation of Color Match, Contour, Consistency, Contiguity or Blending, and Degree of Keloid Formation ( $\mathrm{n}=16$ in both groups)

\begin{tabular}{lcc}
\hline & GTRC & SCTG \\
\hline Color match & & \\
Excellent & 15 & 11 \\
Good & 0 & 5 \\
Adequate & 1 & 0 \\
Unsatisfactory & 0 & 0 \\
Contour & & \\
Good & 15 & 13 \\
Poor & 0 & 1 \\
Irregular & 1 & 2 \\
Consistency & & \\
Firm & 16 & 16 \\
Spongy & 0 & 0 \\
Contiguity & & \\
Yes & & 14 \\
No & 16 & 2 \\
Keloid formation & 0 & 15 \\
Absent & & 1 \\
Present & 16 & \\
\hline
\end{tabular}

not measured in this study, a review of clinical slides taken for each case seems to support this general premise. This is also in agreement with the suggestion by Allen and Miller, who proposed that $1 \mathrm{~mm}$ of tissue thickness may be important when a coronally positioned graft is used for root coverage. ${ }^{34}$ Observation from our study hints that GTR-based root coverage should be attempted only in areas with thick tissues (i.e., $\geq 0.5 \mathrm{~mm}$ ).
The amount of root coverage obtained with collagen membranes in the present study is comparable to that reported in previous studies using both bioabsorbable and non-resorbable membranes. ${ }^{17,35-37}$ However, the results reported here are slightly less favorable than those reported in several other studies; this may be due to variation in materials used and measurement techniques employed. For example, a measurement resolution of $0.5 \mathrm{~mm}$ was used in this study compared to $1.0 \mathrm{~mm}$ in other studies. ${ }^{11,33,38,39}$ Furthermore, our finding of $84 \%$ mean root coverage using SCTG is in general agreement with reports by Raetzke $(80 \%)^{4}$ and Jepsen et al. (87\%). ${ }^{17}$ These results are within the range of $65 \%$ to $98 \%$ mean root coverage where SCTG has been reported. ${ }^{40-42}$

Although both procedures demonstrated an improvement in RW at 6 months, SCTG showed a statistically significant improvement over GTRC. Our results with SCTG were comparable to those reported by Muller et al., who reported 53\% RW coverage at 1 year. ${ }^{43}$ It is possible that differences seen in RW between SCTG and GTRC may be due to inherent differences between the thickness of the donor tissue ( 0.75 to $1.50 \mathrm{~mm})$ and the collagen membrane used here $(0.4$ to $0.5 \mathrm{~mm})$.

Table 7.

Patient Satisfaction With Esthetics ( $\mathrm{n}=16$ in both groups)

\begin{tabular}{lcc}
\hline & GTRC & SCTG \\
\hline Color match & & \\
Excellent & 6 & 9 \\
Good & 8 & 5 \\
Fair & 2 & 1 \\
No response & 0 & 1 \\
Overall satisfaction & & \\
Excellent & 9 & 7 \\
Good & 4 & 6 \\
Fair & 3 & 2 \\
No response & 0 & 1 \\
Amount of root coverage & & \\
Excellent & 7 & 10 \\
Good & 6 & 4 \\
Fair & 2 & 0 \\
No response & 1 & 2 \\
\hline
\end{tabular}


A previous study by this research group reported a $0.9 \mathrm{~mm}$ gain in KG when the GTRC technique was used. ${ }^{12}$ Our current findings closely approximate this result in that GTRC therapy resulted in a $0.7 \mathrm{~mm}$ gain in KG (as compared to $1.1 \mathrm{~mm}$ for SCTG). These results are also in general agreement with previous studies comparing GTRC and SCTG technique for root coverage. ${ }^{39-42}$

In the present report, GTRC and SCTG-treated sites gained $2.8 \mathrm{~mm}$ and $2.3 \mathrm{~mm}$ of CAL, respectively. This was accompanied by a reduction of $0.3 \mathrm{~mm}$ (GTRC) and an increase of $0.4 \mathrm{~mm}$ (SCTG) in probing depth, results that are less than those reported by previous studies (range 2.6 to $5.1 \mathrm{~mm}$ ). ${ }^{35-39}$ These differences in outcomes are difficult to explain but may be partially based on characteristics unique to each individual study including the demographics of study participants, size of the defects treated, measurement techniques employed, operator experience/surgical skills, as well as individual patient factors (e.g., root prominence, depth of the vestibule, soft tissue quality, and compliance). Considering that root coverage was achieved in these situations, this finding illustrates a gain in clinical attachment and suggests formation of a new attachment on a portion of the covered root surface. In the absence of histological evidence, it is impossible to determine whether this gain in attachment is facilitated by formation of a long junctional epithelium, a new connective tissue attachment, or a combination of both types of healing. However, Vincenzi et al. ${ }^{10}$ and Parma-Benfenati and Tinti, ${ }^{18}$ using human histologic material, have shown that root coverage utilizing the principle of GTR can be accompanied by formation of a new fibrous periodontal attachment. Additional studies are needed to understand the interaction between the newly covered root surface and overlying gingival tissues.

Clinical parameters (e.g., PI, GI, and BI) remained relatively constant at all time intervals during the experimental period, suggesting that both treatments were well tolerated by the host tissues. This implies that collagen is a safe clinical material, since it did not enhance plaque accumulation or gingival inflammation. This observation is in agreement with Blumenthal ${ }^{21}$ as well as our previous studies. ${ }^{12,19}$ However, for either therapy, there was an inverse relationship between root coverage/CAL gain and postoperative complication. This finding suggests that postsurgical wound management is critical to the success of root coverage regardless of the treatment type used.

An interesting observation in this study was that both clinicians and patients viewed the 2 techniques as equivalent in terms of outcomes and overall satisfaction. Subjects reported greater overall satisfaction with the GTRC technique, possibly explained by elimination of the need for a second surgical procedure and reduction of treatment time.
Several questions remain to be answered following this study. Although results following either procedure appear equivalent, a longer follow-up period appears warranted. We are also unaware of how important thickness of the graft material (or GTR membrane) is to the final result. Hence, it would be advantageous to design other studies, human or animal, to study this variable. Finally, in the absence of histological evidence, we cannot ascertain if healing following GTRC is via a long junctional epithelium, connective tissue adaptation, new attachment, or other phenomena. Animal-based studies are currently being conducted to learn more about these variables and the tissue dynamics accompanying healing following root coverage procedures.

In conclusion, results from this limited study indicate GTRC or SCTG is clinically comparable (e.g., root coverage and attachment gain at 6 months). An important clinical advantage in using a modified collagen membrane to attain root coverage is that it alleviates the need for donor site procurement of connective tissue.

\section{ACKNOWLEDGMENTS}

The authors wish to thank Ms. Bonnie Loepke, Sandra Hahn, and Cynthia Tsoukalas for their assistance in this project. This study was supported by a grant from Sulzer Calcitek Inc., Carlsbad, California. The authors do not have any financial interests, either directly or indirectly, in the products listed in this study.

\section{REFERENCES}

1. Matter J. Free gingival graft and coronally repositioned flap. A 2-year follow-up report. J Clin Periodontol 1979; 6:437-442.

2. Guinard EA, Caffesse RG. Treatment of localized gingival recessions. III. Comparison of results obtained with lateral sliding and coronally repositioned flaps. J Periodontol 1978;49:457-461.

3. Langer B, Langer L. Subepithelial connective tissue graft technique for root coverage. J Periodontol 1985;56:715720.

4. Raetzke PB. Covering localized areas of root exposure employing the "envelope" technique. J Periodontol 1985;56:397-402.

5. Nelson SW. The subepithelial connective tissue graft. A bilaminar reconstructive procedure for the coverage of denuded root surfaces. J Periodontol 1987;58:95-102.

6 . Harris RJ. A comparative study of root coverage obtained with guided tissue regeneration utilizing a bioabsorbable membrane versus the connective tissue with partialthickness double pedicle graft. J Periodontol 1997;68: 779-790.

7. Tinti C, Vincenzi G, Cocchetto R. Guided tissue regeneration in mucogingival surgery. J Periodontol 1993;64: 1184-1191.

8. Scabbia A, Trombelli L. Long-term stability of the mucogingival complex following guided tissue regeneration in gingival recession defects. J Clin Periodontol 1998;25:1041-1046.

9. Trombelli L, Scabbia A, Tatakis DN, Checchi L, Calura G. Resorbable barrier and envelope flap surgery in the treatment of human gingival recession defects. Case reports. J Clin Periodontol 1998;25:24-29. 
10. Vincenzi G, De Chiesa A, Trisi P. Guided tissue regeneration using a resorbable membrane in gingival recession-type defects. A histologic case report in humans. Int J Periodontics Restorative Dent 1998;18:25-33.

11. Roccuzzo M, Lungo M, Corrente G, Gandolfo S. Comparative study of a bioresorbable and a non-resorbable membrane in the treatment of human gingival recessions. J Periodontol 1996;67:7-14.

12. Shieh A-T, Wang H-L, O'Neal R, Glickman GN, MacNeil RL. Development and clinical evaluation of a root coverage procedure utilizing a collagen membrane. J Periodontol 1997;68:770-778.

13. Tinti C, Vincenzi G, Cortellini P, Pini Prato G, Clauser C. Guided tissue regeneration in the treatment of human facial recession. A 12-case report. J Periodontol 1992; 63:554-560.

14. Ricci G, Silvestri M, Tinti C, Rasperini G. A clinical/statistical comparison between the subpedicle connective tissue graft method and the guided tissue regeneration technique in root coverage. Int $J$ Periodontics Restorative Dent 1996:16:539-545.

15. Cortellini P, Pini Prato G, De Sanctis M, Baldi C, Clauser C. Guided tissue regeneration procedure in the treatment of a bone dehiscence associated with a gingival recession: A case report. Int $J$ Periodontics Restorative Dent 1991;11:460-467.

16. Zucchelli G, Clauser C, De Sanctis M, Calandriello $M$. Mucogingival versus guided tissue regeneration procedures in the treatment of deep recession type defects. $J$ Periodontol 1998;69:138-145.

17. Jepsen K, Heinz B, Halben JH, Jepsen S. Treatment of gingival recession with titanium-reinforced barrier membranes versus connective tissue grafts. $J$ Periodontol 1998;69:383-391.

18. Parma-Benfenati S, Tinti C. Histologic evaluation of new attachment utilizing a titanium-reinforced barrier membrane in a mucogingival recession defect. A case report. $J$ Periodontol 1998;69:834-839.

19. Wang H-L, O'Neal R, Thomas C, Shyr Y, MacNeil RL. Evaluation of an absorbable collagen membrane in treating class II furcation defects. J Periodontol 1994;65:1029-1036.

20. Black BS, Gher ME, Sandifer JB, Fucini SE, Richardson AC. Comparative study of collagen and expanded polytetrafluoroethylene membranes in the treatment of human class II furcation defects. J Periodontol 1994; 65:598-604.

21. Blumenthal NM. The use of collagen membranes to guide regeneration of new connective tissue attachment in dogs. J Periodontol 1988;59:830-836.

22. Wang H-L, MacNeil RL, Shieh A-T, O'Neal R. Utilization of an absorbable collagen membrane in repairing gingival recession defects. Practical Periodontics Aesthet Dent 1996;8:441-448.

23. Postlethwaite AE, Seyer JM, Kang AH. Chemotactic attraction of human fibroblasts for Type I, II and III collagen and collagen derived peptides. Proc Natl Acad Sci (USA) 1978;75:871-875.

24. Steinberg AD, LeBreton G, Willey R, Mukherjee S, Lipowski J. Extravascular clot formation and platelet activation on variously treated root surfaces. $J$ Periodontol 1986;57:516-522.

25. Pitaru S, Tal H, Soldinger $M$, Noff $M$. Collagen membranes prevent apical migration of epithelium and support new connective tissue attachment during periodontal wound healing in dogs. J Periodont Res 1989;24:247253.

26. Zahedi S, Bozon C, Brunel G. A 2-year clinical evaluation of a diphenylphosphorylazide-cross-linked collagen membrane for the treatment of buccal gingival recession.
J Periodontol 1998;69:975-981.

27. Özcan G, Kurtis B, Balos K. Combined use of root conditioning, fibrin-fibronectin system and a collagen membrane to treat a localized gingival recession: A 10-case report. J Marmara Univ Dent Fac 1997;2:588-598.

28. Tatakis DN, Trombelli L. Gingival recession treatment: Guided tissue regeneration with bioabsorbable membrane versus connective tissue graft. J Periodontol 2000; 71:299-307.

29. Miller PD. A classification of marginal tissue recession. Int J Periodontics Restorative Dent 1985;5(2):8-13.

30. O'Leary TJ, Drake RB, Naylor JE. The plaque control record. J Periodontol 1972;43:38.

31. Silness P, Löe H. Periodontal disease in pregnancy. II. Correlation between oral hygiene and periodontal condition. Acta Odontol Scand 1964;22:121-135.

32. Lobene RR, Weatherford T, Ross NM, Lamm R, Menaker L. A modified gingival index for use in clinical trials. Clin Prev Dent 1986;8:3-6.

33. Mühlemann HR, Son S. Gingival sulcus bleeding-a leading symptom in initial gingivitis. Helv Odont Acta 1971; 15:107-113.

34. Allen EP, Miller PD. Coronal positioning of existing gingiva; short-term results in the treatment of shallow marginal tissue recession. J Periodontol 1989;60:316-319.

35. Pini Prato G, Tinti C, Vincenzi G, Magnani C, Cortellini $\mathrm{P}$, Clauser $\mathrm{C}$. Guided tissue regeneration versus mucogingival surgery in the treatment of human buccal gingival recession. J Periodontol 1992;63:919-928.

36. Tinti C, Vincenzi P. Expanded polytetrafluoroethylene titanium-reinforced membranes for regeneration of mucogingival recession defects. A 12-case report. J Periodontol 1994;65:1088-1094.

37. Trombelli L, Schincaglia G, Checchi L, Calura G. Combined guided tissue regeneration, root conditioning, and fibrin-fibronectin system application in the treatment of gingival recession. A 15-case report. J Periodontol 1994; 65:796-803.

38. Trombelli L, Schincaglia GP, Scapoli C, Calura G. Healing response of human buccal gingival recessions treated with expanded polytetrafluoroethylene membranes. A retrospective report. J Periodontol 1995;66:14-22.

39. Trombelli L, Schincaglia GP, Zangari F, Griselli A, Scabbia A, Calura G. Effects of tetracycline $\mathrm{HCl}$ conditioning and fibrin-fibronectin system application in the treatment of buccal gingival recession with guided tissue regeneration. J Periodontol 1995;66:313-320.

40. Jahnke PV, Sandifer JB, Gher ME, Gary JL, Richardson AC. Thick free gingival and connective tissue autografts for root coverage. J Periodontol 1993;64:315-322.

41. Bouchard P, Etienne D, Ouhayoun JP, Nilveus R. Subepithelial connective tissue grafts in the treatment of gingival recessions. Comparative study of 2 procedures. $J$ Periodontol 1994;65:929-936.

42. Wennstrom JL, Zucchelli G. Increased gingival dimensions. A significant factor for successful outcome of root coverage procedures? A 2-year prospective clinical study. J Clin Periodontol 1996;23:770-777.

43. Muller HP, Eger T, Schorb A. Gingival dimensions after root coverage with free connective tissue grafts. J Clin Periodontol 1998;25:424-430.

Send reprint requests to: Dr. Hom-Lay Wang, Department of Periodontics/Prevention/Geriatrics, University of Michigan School of Dentistry, 1011 N. University Avenue, Ann Arbor, MI 48109-1078. Fax: 734/936-0374; e-mail: homlay@umich.edu.

Accepted for publication March 23, 2001. 